\title{
Connecting ecohydrology and hydropedology in desert shrubs: stemflow as a source of preferential flow in soils
}

\author{
Xiao-Yan Li ${ }^{1,2}$, Zhi-Peng Yang ${ }^{2}$, Yue-Tan $\mathrm{Li}^{2}$, and Henry $\mathrm{Lin}^{3}$ \\ ${ }^{1}$ State Key Laboratory of Earth Surface Processes and Resource Ecology, Beijing Normal University, Beijing 100875, China \\ ${ }^{2}$ College of Resources Science and Technology, Beijing Normal University, Beijing 100875, China \\ ${ }^{3}$ Dept. of Crop and Soil Sciences, 116 ASI Building, The Pennsylvania State Univ., University Park, PA 16802, USA
}

Received: 20 January 2009 - Published in Hydrol. Earth Syst. Sci. Discuss.: 4 March 2009

Revised: 29 June 2009 - Accepted: 2 July 2009 - Published: 14 July 2009

\begin{abstract}
Ecohydrology and hydropedology are two emerging fields that are interconnected. In this study, we demonstrate stemflow hydrology and preferential water flow along roots in two desert shrubs ( $H$. scoparium and $S$. psammophila) in the south fringe of Mu Us sandy land in North China. Stemflow generation and subsequent movement within soil-root system were investigated during the growing seasons from 2006 to 2008 . The results indicated that the amount of stemflow in $H$. scoparium averaged $3.4 \%$ of incident gross rainfall with a range of $2.3-7.0 \%$, while in $S$. psammophila stemflow averaged $6.3 \%$ with a range of $0.2-$ $14.2 \%$. Stemflow was produced from rainfall events with total amount more than $1 \mathrm{~mm}$ for both shrubs. The average funneling ratio (the ratio of rainfall amount delivered to the base of the tree to the rainfall that would have reached the ground should the tree were not present) was 77.8 and 48.7 for H. scoparium and S. psammophila, respectively, indicating that branches and stems were fully contributing to stemflow generation and thereby provided sources of water for possible preferential flow into deeper soil layer. Analysis of Rhodamine-B dye distribution under the shrubs showed that root channels were preferential pathways for the movement of most stemflow water into the soil. Distribution of soil water content under the shrubs with and without stemflow ascertained that stemflow was conducive to concentrate and store water in deeper layers in the soil profiles, which may create favorable soil water conditions for plant growth under arid conditions. Accordingly, a clear linkage between aboveground ecohydrology and belowground hydropedology in the desert shrubs is worth noticing, whereby an increase in stemflow would result in an increase in soil hydrologic heterogeneity.
\end{abstract}

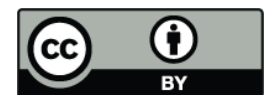

Correspondence to: Xiao-Yan $\mathrm{Li}$ (xyli@ires.cn)

\section{Introduction}

Ecohydrology and hydropedology are two emerging fields that are interconnected within soil-plant-atmosphere continuum in water-limited ecosystems. The integrated interdisciplinary research of hydropedology and ecohydrology would enhance our understanding of the interactions between soil, water, and biological factors in the "Critical Zone" (National Research Council, 2001; Lin, 2003; Lin et al., 2005; Newman et al., 2006; Brantley et al., 2006; Young et al., 2007). Vegetation plays an important role affecting ecohydrological and hydropedological processes at the local and catchment scales because of the control that vegetation canopies exert on the redistribution of incident precipitation (CarlyleMoses, 2004; Owens et al., 2006) and plant roots exert on water and nutrient transport in the vadose zone (Devitt and Smith, 2002; Skaggs and Shouse, 2008). Vegetation canopies can affect the vertical and horizontal spatial distribution of water within the plant community (Owens et al., 2006). Partition of precipitation by vegetation canopy comprises three fractions: (1) interception, which is retained on the vegetation and is evaporated after or during rainfall; (2) throughfall, which reaches ground by passing directly through or dripping from tree canopies, and (3) stemflow, which flows to the ground via trunks or stems (Crockford and Richardson, 2000; Carlyle-Moses and Price, 2006). Canopy interception generally exerts a negative effect on the horizontal distribution of water by retaining small pulses of precipitation in the canopy (Loik et al., 2004; Owens et al., 2006; Llorens and Domingo, 2007) and preventing water from reaching the ground surface. Throughfall affects surface soil layers and moisture distribution, while stemflow can alter the vertical distribution of water by funneling water to the base of plants where it can infiltrate preferentially (Devitt and Smith, 2002; Llorens and Domingo, 2007) or be redistributed through diffusion or hydraulic lift (Schwinning

Published by Copernicus Publications on behalf of the European Geosciences Union. 
and Sala, 2004; Owens et al., 2006). Johnson and Lehmann (2006) reviewed that tree redistributed hydrologic fluxes to the root zone through a double-funneling process: (1) tree first partitions rainfall into throughfall and stemflow, resulting in a spatial redistribution of water fluxes reaching the soil; and (2) stemflow delivered to the soil at the base of trees is then further funneled by tree roots through belowground preferential flow pathways. Levia and Frost (2003) reviewed the quantitative and qualitative importance of stemflow in forested and agricultural ecosystems, and pointed out that stemflow was a spatially localized point input of precipitation and solutes at the plant stems and was of hydrological and ecological significance. Stemflow values usually are less than $5 \%$ of annual rainfall but can reach 22 to $40 \%$ in some cases (Slatyer, 1965; Pressland, 1973; Navar and Ryan, 1990; Carlyle-Moses and Price, 2006; Li et al., 2008). Johnson and Lehmann (2006) found that stemflow can vary by more than three orders of magnitude, from $0.07 \%$ to $22 \%$ of incident rainfall, under a wide range of precipitation regimes $\left(600-7100 \mathrm{~mm} \mathrm{y}^{-1}\right)$. Levia and Frost (2003) reported the mean maximum stemflow values of approximately $3.5 \%, 11.3 \%$, and $19 \%$ for tropical, temperate, and semiarid regions, respectively. Stemflow is highly variable between and within types of vegetation, as reviewed by Lorens and Domingo (2007). For example, Lorens and Domingo (2007) found that although stemflow averaged 3\% of incident precipitation under Mediterranean conditions, there was an associated coefficient of variation of $111 \%$.

Although stemflow may be volumetrically minor compared to throughfall at the stand scale, it has a significant influence on runoff generation, soil erosion, groundwater recharge, soil moisture, plant nutrients, and the spatial distribution of understory vegetation and epiphytes (Levia and Frost, 2003; Carlyle-Moses and Price, 2006; Li et al., 2008). Stemflow always results in spatial heterogeneity in soil-water fluxes due to stemflow and root channelization processes. In a study in Western Australia, root channels beneath eucalypt forest provided conduits for the penetration of rain water to a depth of $12 \mathrm{~m}$ over a period of 20 years, whilst rainwater on wheat lands in the same area had penetrated no deeper than $2.5 \mathrm{~m}$ (Allison and Hughes, 1983; Maitre et al., 1999). Nulsen et al. (1986) found that the canopy of mallee vegetation intercepts rainwater and redistributes it into soil via stemflow at depths as great as $28 \mathrm{~m}$. The flow of water through stem-root system often occurs as preferential flow. Devitt and Smith (2002) reported that macropores formed by the root systems of woody shrubs may be an important conduit for downward water movement in desert soils. Stemflow could be an important source of soil moisture in arid and semiarid lands (Tromble, 1987). Mauchamp and Janeau (1993) reported that Flourensiacernua was capable of channeling approximately $50 \%$ of the incident gross precipitation to the plant stem. Navar and Bryan (1990) calculated that the stemflow inputs to the soil around three semiarid shrub stems in northeastern Mexico represented a water input that was five times that received by other areas below the shrub canopies. Moreover, other arid and semiarid shrubs like Banksia ornate, Xantohorrea australis, Haloxylon aphyllum, Acacia aneura, Diospyrus texana, Acacia farnesiana, Tamarix ramosissima, Caragana korshinskii and Reaumuria soongorica are also adapted to divert rainfall to the base of their stems as stemflow where it subsequently infiltrates the soil and remains available for plant uptake in the deeper soil layers (Pressland, 1976; Nulsen et al., 1986; Navar, 1993; Martinez-Meza and Whitford, 1996; Lorens and Domingo, 2007; Li et al., 2008). This deep infiltrated water is considered as a possible source of available moisture for shrub growth in desert ecosystems even in the absence of accessible water in the upper soil profile (Tromble, 1987). Martinez-Meza and Whitford (1996) hypothesized that the stemflow-root channelization process by shrubs was an adaptive mechanism used to survive seasonal drought, a process referred to as the "nursing effect" by Goodall (1965). However, water utilization by plants is controlled by many factors (such as vegetation types, soil moisture storage and redistribution, depth of root and bedrock, and frequency of rainfall events), thus the extent and importance of stemflow used by plants are not generally well understood (Maitre et al., 1999).

Stemflow hydrology and preferential water flow along roots in the soil are intimately linked. Stemflow hydrology involves stemflow generation and water chemistry change as influenced by meteorological conditions, seasonality, species-specific traits, and canopy structure (Levia and Frost, 2003). Despite the recognition of potentially large effect of stemflow and associated processes on the hydrologic budget, few, if any, experimental studies have simultaneously evaluated the hydrologic fluxes redistributed by aboveground shrub stems and below-ground roots with stemflow and preferential flow, respectively, under natural rainfall conditions. In recent decades, stemflow-root channelization process in the soil has received considerable attention (Pressland, 1976; Nulsen et al., 1986; Navar, 1993; Martinez-Meza and Whitford, 1996; Lorens and Domingo, 2007; Segal et al., 2008); however, available data about the interconnection between stemflow and water flow in soil profile remain scarce. For example, stemflow dynamics, velocity, and pathway in relation to rainfall characteristics and vegetation species remain elusive, and the subsequent movement of stemflow water within soil-root system under different canopies and soil conditions is not well understood for plant survival in waterlimited ecosystems. Therefore, the objective of this study was to make an attempt to connect ecohydrology and hydropedology through an integrated study of stemflow generation and subsequent water movement in soils. We used a combination of stemflow collection with real-time rainfall monitoring, dye tracing, and soil profile moisture monitoring under two desert shrub species in the south fringe of Mu Us sandy land of North China. 


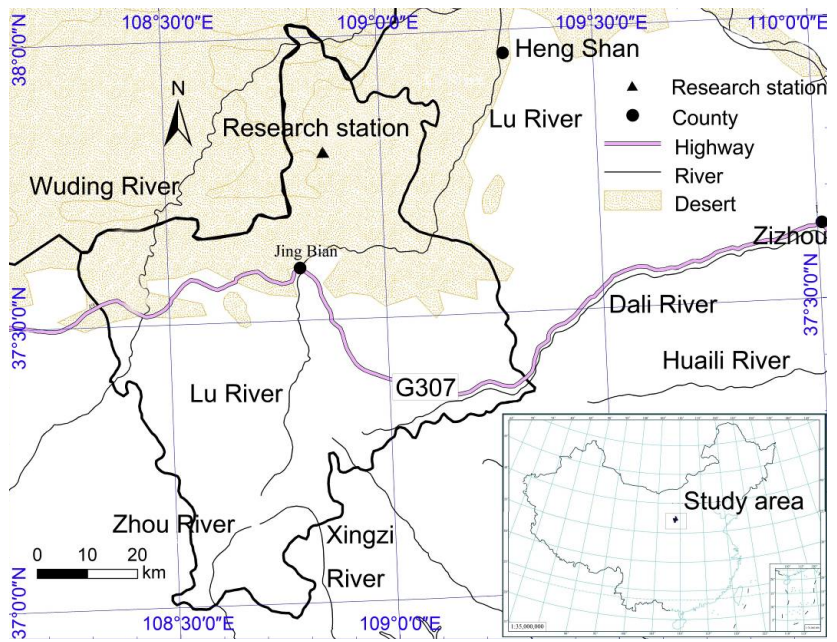

Fig. 1. Location of the study area.

\section{Materials and methods}

\subsection{Study area}

The study was conducted at Yulin Experimental Station of Mu Us Sandy Land Ecosystem of Beijing Normal University in Jingbian County, Shaanxi Province, North China $\left(37^{\circ} 38^{\prime} \mathrm{N}, 108^{\circ} 50^{\prime} \mathrm{E}, 1350 \mathrm{~m}\right.$ a.s.l.) (Fig. 1). The Mu Us sandy land lies in the transitional zone from typical steppes to deserts. It has a semi-arid continental climate, and is highly susceptible to wind erosion (Runnstrom, 2003). The widespread coating of the Quaternary aeolian sand dunes on the Cretaceous rocks favors shrubs over trees and grasses to such an extent that at least 117 shrub and semi-shrub species have been observed within the Mu Us sandy land (Dong and Zhang, 2001).

The study site lies in the south fringe of Mu Us sandy land. Mean annual precipitation is $395 \mathrm{~mm}$, more than $60 \%$ of which occurs between July and September. Mean annual temperature is $7.9^{\circ} \mathrm{C}$ and annual pan evaporation is $2485 \mathrm{~mm}$. Psammophytic half-shrub communities are the main vegetation, dominant species being Salix psammophila, Artemisia ordosica, Hedysarum scoparium, Hedysarum laeve, Psammochloa villosa (Chen et al., 2002). We selected S. psammophila and $H$. scoparium to investigate the characteristics of stemflow generation and its hydropedological effects. The soil (Typic Ustipsamment) is an aeolian sand with uniform texture throughout the profile ( $98.48 \%$ sand, $1.52 \%$ silt, and $0 \%$ clay). Average soil organic matter and total $\mathrm{N}$ concentration in the $0-100 \mathrm{~cm}$ layer are 0.64 and $0.068 \mathrm{~g} \mathrm{~kg}^{-1}$, respectively (Wang et al., 2006).

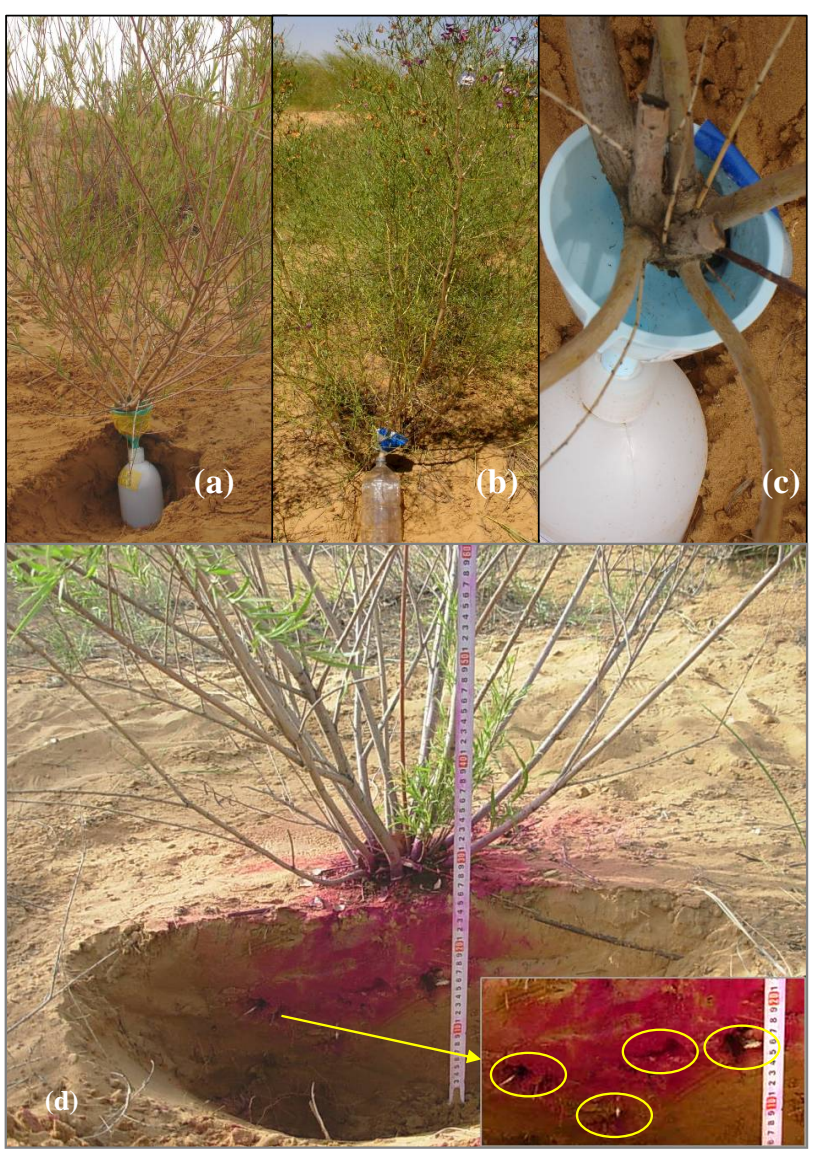

Fig. 2. Photographs showing shrubs of $S$. psammophila (a) and $H$. scoparium (b), stemflow collector consisting of plastic funnel and a collection bottle (c) and a vertical profile of dye stained area (d) under S. psammophila with several root channels indicated (marked by the yellow elliptic frames).

\subsection{Experimental design}

\subsubsection{Stemflow characteristics}

To investigate stemflow characteristics of $S$. psammophila (Fig. 2a) and H. scoparium (Fig. 2b), we measured stemflow from 14 mature plants representing the two shrub species (7 samples for each species). Stemflow volumes were determined on a rainfall event basis during rainy seasons between June and September from 2006 to 2008. Stemflow drainage was collected using plastic funnels fitted around the main stems and sealed with silicone sealant. The funnels were connected via plastic tubes to a collecting bottle where the stemflow was stored (Fig. 2c). We measured stemflow by hand using graduated cylinder after each rainfall event. Stemflow volume of each plant was divided by its canopy area to calculate the stemflow depth on a stand basis. Total incident rainfall was measured automatically with a tipping bucket rain gauge (Delta-T, Cambridge, UK) located $20 \mathrm{~m}$ away 
Table 1. Mean values ( \pm standard deviation) of morphological parameters of the two dessert shrub species studied $(n=12)$.

\begin{tabular}{lcc}
\hline & H. scoparium & S. psammophila \\
\hline Shrub height $(\mathrm{m})$ & $1.7 \pm 0.3$ & $2.1 \pm 0.2$ \\
Branch angle $\left({ }^{\circ}\right)$ & $70.5 \pm 10.0$ & $61.8 \pm 6.5$ \\
Basal area $\left(\mathrm{cm}^{2}\right)$ & $3.9 \pm 1.8$ & $10.9 \pm 8.3$ \\
Number of branches & $13 \pm 9$ & $6 \pm 2$ \\
Canopy area $\left(\mathrm{m}^{2}\right)$ & $2.7 \pm 0.6$ & $3.6 \pm 3.1$ \\
\hline
\end{tabular}

from the study plots in an open area. Canopy variables that were measured on each shrub included shrub height, number of branches, branch angle, canopy height, basal area, and canopy area (Table 1) using methods of Martinez-Meza and Whitford (1996). Shrub height was measured at the centre of the canopy, basal area was calculated with collar girth at the base, canopy area was calculated by taking the east-west and north-south diameters through the centre of the fullest part of the canopy.

To determine the extent to which the branches of shrubs spatially concentrate stemflow inputs and operate as a collection of incident gross precipitation, the Herwitz funneling ratio $(F)$ was calculated as (Herwitz, 1986):

$$
F=\frac{V}{B \times P}
$$

where $V$ is stemflow volume (L), $B$ is trunk basal area $\left(\mathrm{m}^{2}\right)$, and $P$ is the depth equivalent of gross incident precipitation (mm). The product $B \times P$ provides the volume of water that would have been caught by a rain gauge having an opening equal to that of the trunk basal area. Thus, $F$ represents the ratio of the amount of precipitation delivered to the base of the shrub to the rainfall that would have reached the ground if the shrubs were not present (Carlyle-Moses and Price, 2006). Funneling ratios higher than unity indicate that canopy components other than the trunk are contributing to stemflow (Herwitz, 1986; Carlyle-Moses and Price, 2006).

\subsubsection{Dye tracer experiment}

Dyes are commonly used tracers to investigate subsurface water movement (Flury and Wai, 2003). For more than a century, dye tracers have provided clues regarding flow and transport processes in the subsurface. Flury et al. (1994) reported that the disadvantage of dye for tracing water flow paths is that the sampling, i.e., soil excavation, is destructive and experimental results can not be repeated at the same location. However, they also stated that results obtained from staining experiments clearly illustrate the complicated pattern of water movement with a high spatial variability. On the basis of specific criteria such as solubility, sorption, mobility, and stability under different environments, Rhodamine-B dye has been recommended as one of the most suitable tracers (Wilson et al., 1986; Flury and Wai, 2003). MartinezMeza and Whitford (1996) and Devitt and Smith (2002) have used Rhodamine-B dye to illustrate the pattern of water movement in the roots of desert shrub. Therefore, we selected Rhodamine-B dye to trace flow path of stemflow in the root area.

To assess redistribution of stemflow into the soil profile for S. psammophila and H. scoparium, we selected another three plants for each species with growth shape similar to those for stemflow measurements to conduct dye tracer experiments under three natural rainfall events - representing small $(4.9 \mathrm{~mm})$, medium $(9.1 \mathrm{~mm})$, and large $(32 \mathrm{~mm})$ rainfall in the study area. One plant was used for each of the three rainfall events for both $S$. psammophila and $H$. scoparium. The selected plants were a few meters away from those used for measuring stemflow. Rhodamine-B dye powder was sprinkled on the soil surface around the base of the trunk (at the root crown) of the selected shrubs as well as the adjacent bare area without shrubs before rain occurrence (MartinezMeza and Whitford, 1996). Twenty-four hours after rainfall, pits were dug along the main roots beneath the canopy of the shrubs (Fig. 2d), and photographs were taken using a digital camera, and then downloaded and transferred to ArcGIS (ESRI, Redlands, CA) for the dye stain analysis (Devitt and Smith, 2002). Diagrams of the percentage of dye stained area with depth were made according to the procedure of Janssen and Lennartz (2008). Canopy parameters of plants in this part of the study were obtained by the same methodology as that used in the stemflow measurements.

\subsubsection{Soil water content measurements}

To explore the effect of stemflow on soil water recharge, soil water contents were measured under two other plants with similar growth for each of the two shrub species: one was the control with stemflow, and the other without stemflow (which was removed using stemflow collector). Soil water contents were measured using TRIME-PICO IPH time domain reflectometry (TDR) (IMKO, Ettlingen, Germany) to a depth of $100 \mathrm{~cm}$ with sampling increment of $20 \mathrm{~cm}$ after each rainfall event. The TDR access tubes were installed to a depth of $1.2 \mathrm{~m}$ and at $5 \mathrm{~cm}$ from the stem of the shrub. Soil water content measurements were conducted from June to September in 2007 for 8 rainfall events. Soil moisture at each depth was obtained by taking three replicated measurements (through rotating the probe at approximately $120^{\circ}$ ) and calculating the average. We analyzed soil water contents for $H$. scoparium and S. psammophila with and without stemflow under three rainfall events $(4.3,14$ and $32.5 \mathrm{~mm})$ to characterize the distribution of soil water under rainfall of high, medium, and low amounts. Meantime, we compared the differences in soil water contents between the treatments with and without stemflow at the soil depths of 20,60 and $100 \mathrm{~cm}$ for the two shrub species for the 8 rainfall events. 

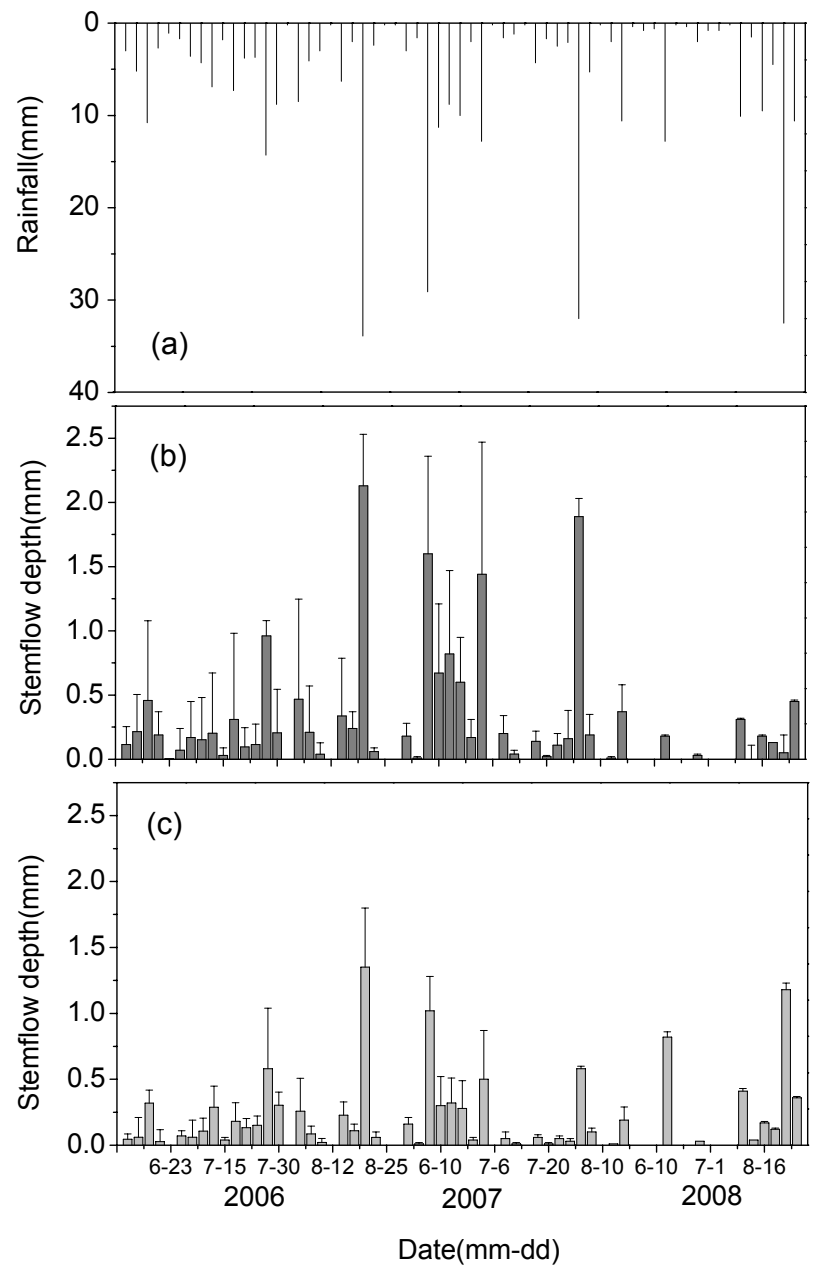

Fig. 3. Daily rainfall distribution (a) together with the stemflow depth (mm) for S. psammophila (b) and H. scoparium (c) from 2006 to 2008 during growing periods at the experimental site (bars indicated standard deviation of the seven replicates for each species).

\section{Results and discussion}

\subsection{Rainfall and stemflow}

During rainy seasons between June and September from 2006 to 2008, a total of 64 rainfall events were recorded with individual rain amount ranging from 1.1 to $33.9 \mathrm{~mm}$. Fifty-three percent of these rainfall events were less than 5 $\mathrm{mm}$ and their contribution to the total rainfall amount during rainy reasons from 2006 to 2008 was less than $17 \%$, while the rains exceeding $10 \mathrm{~mm}$ accounted for $69 \%$ of the total rainfall. Analysis of the rainfall intensity $\left(I_{10}\right.$, maximum rainfall intensity in $10 \mathrm{~min}$ ) showed that the records were in the range of $1.2-57.6 \mathrm{~mm} \mathrm{~h}^{-1}$ and $59 \%$ were less than $5.0 \mathrm{~mm} \mathrm{~h}^{-1}$, whereas rainfall intensity over $20 \mathrm{~mm} \mathrm{~h}^{-1}$ accounted for only $16 \%$ of rainfall events. The results suggest that most storms were of small size with low intensity, and
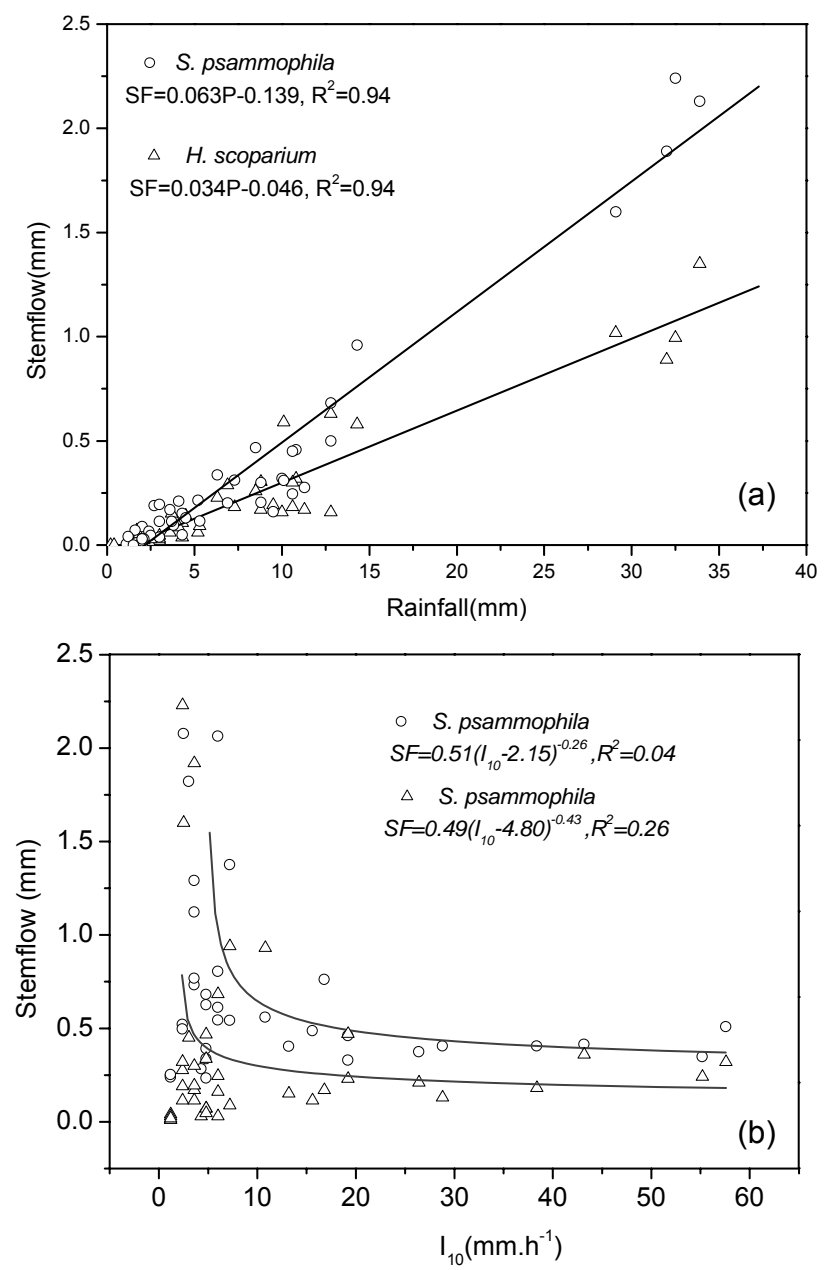

Fig. 4. The relationship between stemflow and daily rainfall amount (a) and maximum Intensity in $10 \mathrm{~min}$ (b) for $H$. scoparium and $S$. psammophila.

the total amount of annual rainfall depended mainly on a few of lager size storms.

Stemflow was measurable only for 49 events $(76.6 \%)$ (Fig. 3), among which the minimum rainfall was $1.1 \mathrm{~mm}$ for S. psammophila and $1.2 \mathrm{~mm}$ for $H$. scoparium, respectively. This suggests that the threshold amount of rainfall for stemflow initiation is slightly over $1 \mathrm{~mm}$ for these two shrubs. This threshold value is comparable with the rainfall threshold of $1.5 \mathrm{~mm}$ reported by Pressland (1973) for A. aneura, 1-2 mm reported by Enright (1987) for Rhopalostylis sap$i d a$, and $1.3-1.8 \mathrm{~mm}$ reported by Martinez-Meza and Whitford (1996) for Larrea tridentata, Prosopis glandulosa and Flourensia cernua.

Individual stemflow was significantly correlated with individual rainfall amount for both shrub specices. Stemflow increased with increasing rainfall depth and followed a positive linear function (Fig. 4a). For the same amount of rainfall, S. psammophila on average produced 1.85 times higher 


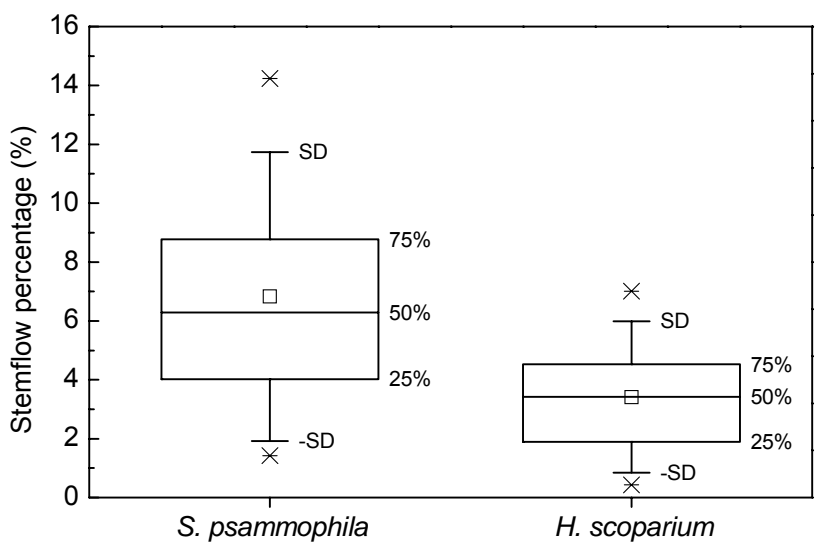

Fig. 5. Box-and-whisker diagrams showing the median, 25th, 50th, 75 th percentiles and standard deviation for individual stemflow percentage of daily rainfall amount for $S$. psammophila and $H$. scoparium. $(\square)$ Represents mean value, $(*)$ maximum and minimum value.

stemflow than H. scoparium. Stemflow amounts in $H$. scoparium averaged $3.4 \%$ of incident gross rainfall with a range of 2.3-7.0\%, while in S. psammophila, stemflow averaged $6.3 \%$ with a range of $0.2-14.2 \%$ (Fig. 5). Higher stemflow production for S. psammophila was likely a result of its larger canopy area, larger basal area, taller shrub height, and smaller branch angel, as compared with $H$. scoparium (Table 1). Several earlier studies have reported positive correlation between stemflow amount and canopy area (Ford and Deans, 1978; Martinez-Meza and Whitford, 1996; Li et al., 2008). The relationship between stemflow and rainfall intensity in this study was weaker but showed a general negative power function (Fig. 4b). Both shrubs showed a decline in stemflow as rainfall intensity increased from $0.2 \mathrm{~mm} \mathrm{~h}^{-1}$ until about $10 \mathrm{~mm} \mathrm{~h}^{-1}$ and then relatively stabilized up to the intensity near $60 \mathrm{~mm} \mathrm{~h}^{-1}$. This supports results of Carlyle-Moses (1996), who found that stemflow significantly $(\alpha=0.05)$ decreased with increasing mean event rainfall intensity in a temperate deciduous stand in southern Ontario, Canada.

Average funneling ratio $(F)$ was 77.8 and 48.7 for $H$. scoparium and $S$. psammophila, respectively, indicating that branches and stem were fully contributing to stemflow generation and thereby provided greater amount of water to the base of the stem. The $H$. scoparium had high variability in $F$, and the largest $F$ value was 203 during a 10.6 -mm rainfall event. In contrast, $S$. psammophila exhibited small variability in $F$ with the largest values of 117 during a $8.8-\mathrm{mm}$ rainfall event. The lower funneling ratio of $S$. psammophila as compared to $H$. scoparium was due to $S$. psammophila's larger basal area (Table 1). From Eq. (1), 1.6 lower $F$ for $S$. psammophila is expected because $S$. psammophila has 1.85 higher stemflow for the same amount of incident rainfall and 2.8 larger basal area. The funneling ratios for $H$. scoparium and
S. psammophila approximately fall within the range of values (7-112) derived by Herwitz (1986) for montane tropical rainforest of Australia. Various other researchers have reported diverse $F$ values for different plants in various environments. For example, Navar (1993) reported that Prosopis laevigata and Acacia farnesiana shrubs had average stemflow funnelling ratios of 11, while ratios for Diospyros texana individuals averaged 58. Herwitz and Levia (1997) found, in a mixed deciduous secondary growth stand in Massachusetts, that the average winter funnelling ratios from five sampled bigtooth aspen (Populus grandidentata) ranged from 5.2 to 14.7. Carlyle-Moses and Price (2006) reported that red oak, sugar maple, and American beech had funneling ratio of 7.3, 20.6, and 26.3, respectively. $\mathrm{Li}$ et al. (2008) found that average funneling ratios were $153.5 \pm 66.2,53.2 \pm 25.7$, and $24.8 \pm 15.3$ for the shrubs of $C$. korshinskii, $R$. soongorica and $T$. ramosissima respectively, in the semiarid loess regions of China. Carlyle-Moses and Price (2006) reviewed studies concerning stemflow funneling ratios and concluded that the funneling ratios found in temperate deciduous forests are similar to those in tropical rainforests, semiarid, and humid Mediterranean environments.

For the two shrub species the relationship between $F$ and incident rainfall amount was found to have a tendency of $F$ first being increased with incident rainfall amount between 1.2 and $12.8 \mathrm{~mm}$, while for the five events $>29 \mathrm{~mm}$ the $F$ values declined (Fig. 6a). We can not completely quantify the relationship between $F$ and rainfall depth because incident rainfall events between 12.8 and $29 \mathrm{~mm}$ were not available in our study. However, our results are consistent with findings of Carlyle-Moses and Price (2006), who found that the event $F$ values for red oak, sugar maple, and American beech increased in a linear fashion between events of 4.3 and $17.4 \mathrm{~mm}$, while for the two events $>17.3 \mathrm{~mm}$ the $F$ values were significantly smaller than would be expected if the linear trends of $F$ versus rainfall amount for the smaller events continued. Li et al. (2008) also found such pattern between $F$ and incident rainfall for $C$. korshinskii, $R$. soongorica and T. ramosissima. Carlyle-Moses and Price (2006) explained that, with increasing rainfall input, a greater proportion of a tree becomes saturated and thus the area contributing to stemflow increases until a threshold rainfall input is reached that saturates all tree areas capable of producing stemflow. Once this threshold rainfall is exceeded, $F$ value begins to decrease. For the relationship between $F$ and rainfall intensity (Fig. 6b), $F$ tended to increase in a linear fashion for events less than $10 \mathrm{~mm} \mathrm{~h}^{-1}$ of $I_{10}$ (the maximum rainfall Intensity in $10 \mathrm{~min}$ ), while $F$ showed a decreasing trend with $I_{10}$ between 10 and $60 \mathrm{~mm} \mathrm{~h}^{-1}$. Such pattern was also reported by Staelens et al. (2008) who found that a significant decrease of stemflow amount was found for events with higher maximal rainfall rates, particularly during the leafed periods. A likely explanation is that intense rain events increase the probability of branch drip by overloading preferential flow paths on tree trunks and forcing 

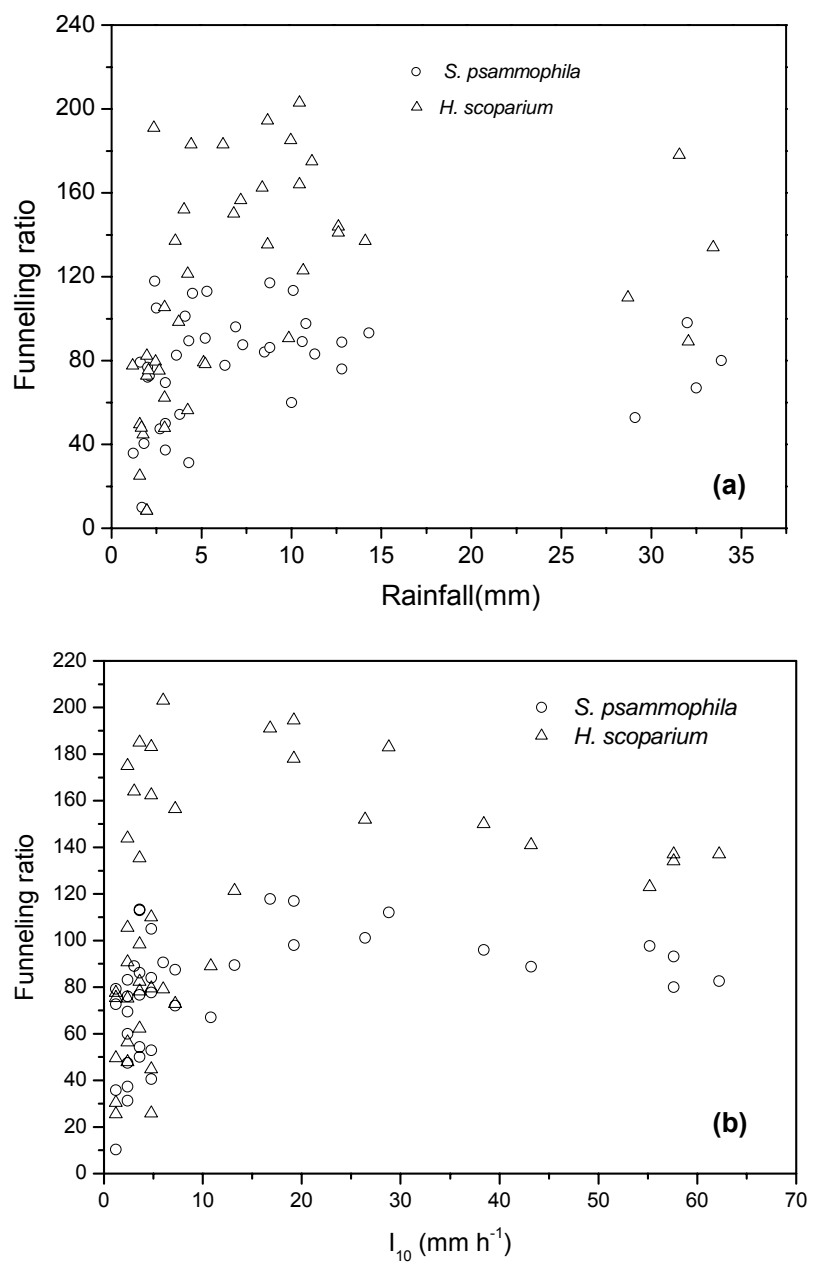

Fig. 6. Relationship between funneling ratio and daily rainfall amount (a) and $I_{10}$ (b) (maximum rainfall Intensity in $10 \mathrm{~min}$ ) for H. scoparium and S. psammophila.

stemflow to become throughfall (Crockford and Richardson, 2000; Staelens et al., 2008). Also, Carlyle-Moses (2004) suggests that the larger rain-drop volume, terminal velocity, and thus kinetic energy associated with high intensity rainfall results in a larger proportion of intercepted precipitation being "splashed" from the canopy surfaces and thus reducing the amount of water available for stemflow production and interception loss. However, Fig. 6 reflects a mixture of different effects of rainfall amount and intensity on stemflow, where the effects of rainfall amount on $F$ might be counteracted by rainfall intensity for intense rain events. This needs further investigation in future study.

\subsection{Dye coverage}

As observed in the field (such as that illustrated in Fig. 7), the dye stained area was significantly influenced by the presence of shrub. In the bare area, the dye coverage was higher but only confined to the upper part of the vertical sectional area with a rather uniform distribution (Fig. $7 \mathrm{~g}, \mathrm{~h}, \mathrm{i}$ ), and the maximum dye stained depth was 8,10 , and $14 \mathrm{~cm}$ for the rainfall of 4.9, 9.1 and $32 \mathrm{~mm}$, respectively (Fig. 8). However, in the area with the shrub, dye movement was localized along main roots where the dye had penetrated farther into the vertical profiles (Fig. 7a-f and Fig. 2d). The maximum depth of dye stain ranged from 18 to $20 \mathrm{~cm}$ for $H$. scoparium and from 20 to $26 \mathrm{~cm}$ for $S$. psammophila, respectively, under the three rainfall events (Fig. 8). The maximum dye depth increased with increasing rainfall for both shrubs. Also, the larger rain produced more uniform flow in the upper soil profile while the smaller rain produced a higher degree of preferential flow pattern (Fig. 7). This may be attributed to the fact that the preferential stemflow effect close to the stem would be masked by throughfall infiltration because a greater proportion of rainfall occurred as throughfall during large rainfall events (Pressland, 1976; Owens et al., 2006).

As far as rainfall intensity is concerned, high intensity rain may be more prone to trigger stemflow as preferential flow. In Fig. 7, the rainfall event of $4.9 \mathrm{~mm}$ with high intensity (average rain intensity of $19.60 \mathrm{~mm} \mathrm{~h}^{-1}$ ) showed apparent deeper wetting front (dye stain area), followed by rainfall events of $32 \mathrm{~mm}$ (average rain intensity of $1.60 \mathrm{~mm} \mathrm{~h}^{-1}$ ) and $9.1 \mathrm{~mm}$ (average rain intensity of $0.76 \mathrm{~mm} \mathrm{~h}^{-1}$ ), indicating that preferential flow was more pronounced under higher rainfall intensity. However, the process of stemflow and preferential flow may compensate at certain rainfall intensity as stemflow decreases with rainfall intensity while preferential flow increases with rain intensity. Dye tracer experiment showed that preferential flow occurrence is linked to the presence of roots (Fig. 2d). This is also confirmed by the findings of Martinez-Meza and Whitford (1996) and Devitt and Smith (2002), who used artificial application of water of higher amount (40-300 mm). In our experiment, we traced stemflow in the soil profile under natural rainfall conditions. Stemflow penetrated as deep as $18 \mathrm{~cm}$ under the rainfall of $4.9 \mathrm{~mm}$, suggesting that stemflow from small rainfall events can also recharge deeper soil in the sandy desert area. de Rooij (2000) and Wang et al. (2003) reported that finger flow resulting from wetting front instability is common in sandy soil, but we did not find finger flow phenomena in this study. This may be attributed to the fact that the presence of shrubs localized stemflow along main roots and thereby channelling water down the root zone. Kung (1990) reported that preferential flow paths constituted dominant flow pattern in a sandy vadose zone, and that water flowing through the root zone was funneled into concentrated flow paths that occupied only a small portion of the soil matrix and yet accounted for most of the transport.

Nutrient enrichment in stemflow could contribute to high organic matter content in the soil close to the plant (Whitford et al., 1997), which may also lead to preferential flow occurrence. Johnson and Lehmann (2006) reviewed that dissolved organic carbon (DOC) concentrations of the stemflow were enriched by $703-2372 \%$ relative to rainfall. In addition, 


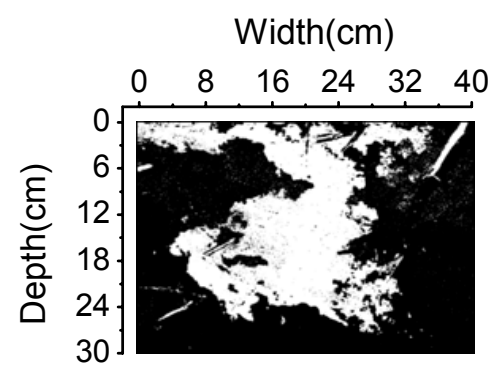

a. H. scoparium/4.9mm
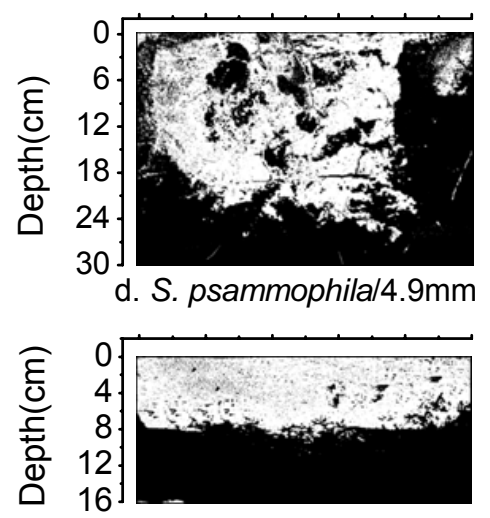

g. Bare area/4.9mm

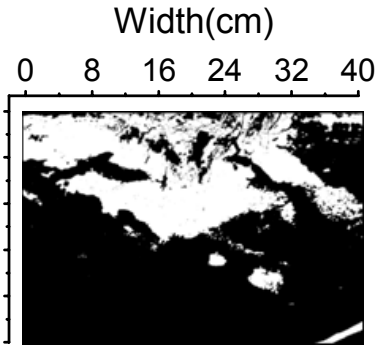

b. H. scoparium/9.1mm

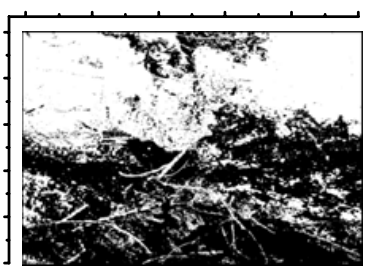

e. S. psammophila/9.1mm

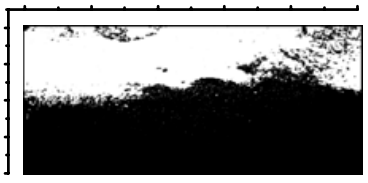

h. Bare area/9.1mm

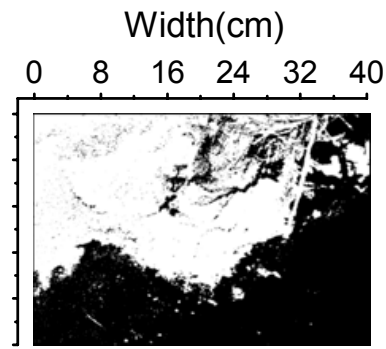

c. H. scoparium $/ 32 \mathrm{~mm}$

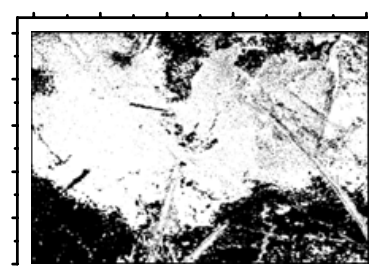

f. S. psammophila/32mm

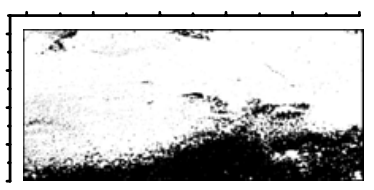

i. Bare area/32mm

Fig. 7. Computer-enhanced photos of the dye stained area in vertical soil profiles exposed around the base of the trunk (see Fig. $2 \mathrm{~d}$ for an actual visualization) beneath the canopy of $H$. scoparium, S. psammophila, and the bare area, respectively, under three rainfall events with amount of 4.9, 9.1 and $32 \mathrm{~mm}$ (the corresponding intensity and duration were 19.6, 0.76, $1.6 \mathrm{~mm} \mathrm{~h}^{-1}$, and $0.25,12,20 \mathrm{~h}$ respectively). White shading indicates dye stained areas, black shading represents unstained conditions. See Fig. 8 for quantitative dye-stained area as a function of soil depth.
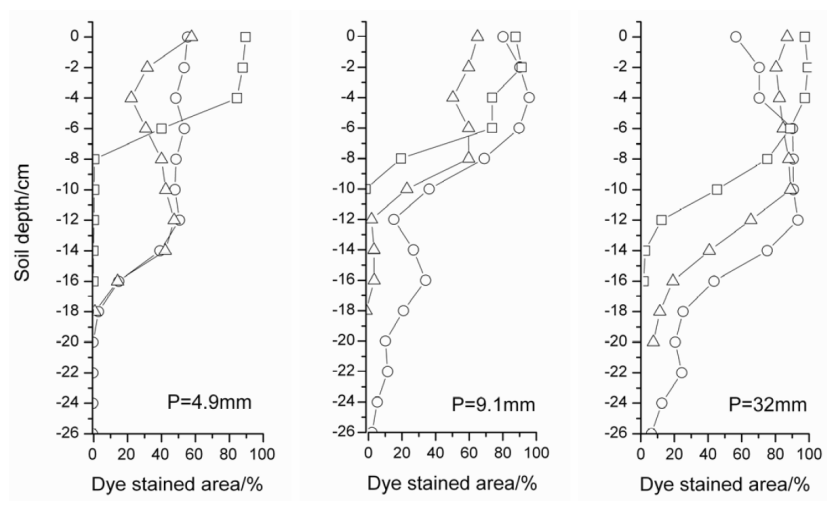

Fig. 8. The percentage of dye stained area with depth for $H$. scoparium $(\triangle), S$. psammophila $(\bigcirc)$ and the bare area $(\square)$ respectively, under three rainfall events with amount of 4.9, 9.1 and $32 \mathrm{~mm}$.

stemflow water contains high concentrations of particulate organic matter (POM) (Parker, 1983). Bundt et al. (2001) reported that soil organic $\mathrm{C}$ concentrations in preferential flow pathways were $10-70 \%$ higher than that in the soil matrix. In our study, soil organic mater was significantly higher (1.0-
$1.6 \mathrm{~g} \mathrm{~kg}^{-1}$ ) in the soil around shrub base of $H$. scoparium and S. psammophila than that in the adjacent bare soil (0.3$\left.0.6 \mathrm{~g} \mathrm{~kg}^{-1}\right)$. This indirectly suggests that stemflow may also induce preferential flow by means of nutrient input to the soil and thus altering soil structure.

\subsection{Soil water content}

Soil water content with soil depth directly reflected the influence of stemflow-root system on water movement. Wetter soil and deeper penetration of the water can be clearly noted when there was stemflow (Fig. 9). During the three rainfall events characterized by small $(4.3 \mathrm{~mm})$, medium $(14 \mathrm{~mm})$ and large $(32.5 \mathrm{~mm})$ amounts, as much as $10-60 \%$ increase in soil water content could be found in S. psammophila and 10-140\% increase in H. scoparium as compared to that without stemflow. However, the magnitude of the effect of stemflow on soil water content seems smaller than would be expected from the funneling ratio values. This may be attributed to funneling ratios expressed in terms of the basal area (Herwitz, 1986) instead of stemflow impacted area. Pressland (1976) found that all stemflow infiltrates into the soil within the area of $50 \mathrm{~cm}$ around large trees with circumferences larger than $40 \mathrm{~cm}$ and within the area of $30 \mathrm{~cm}$ 


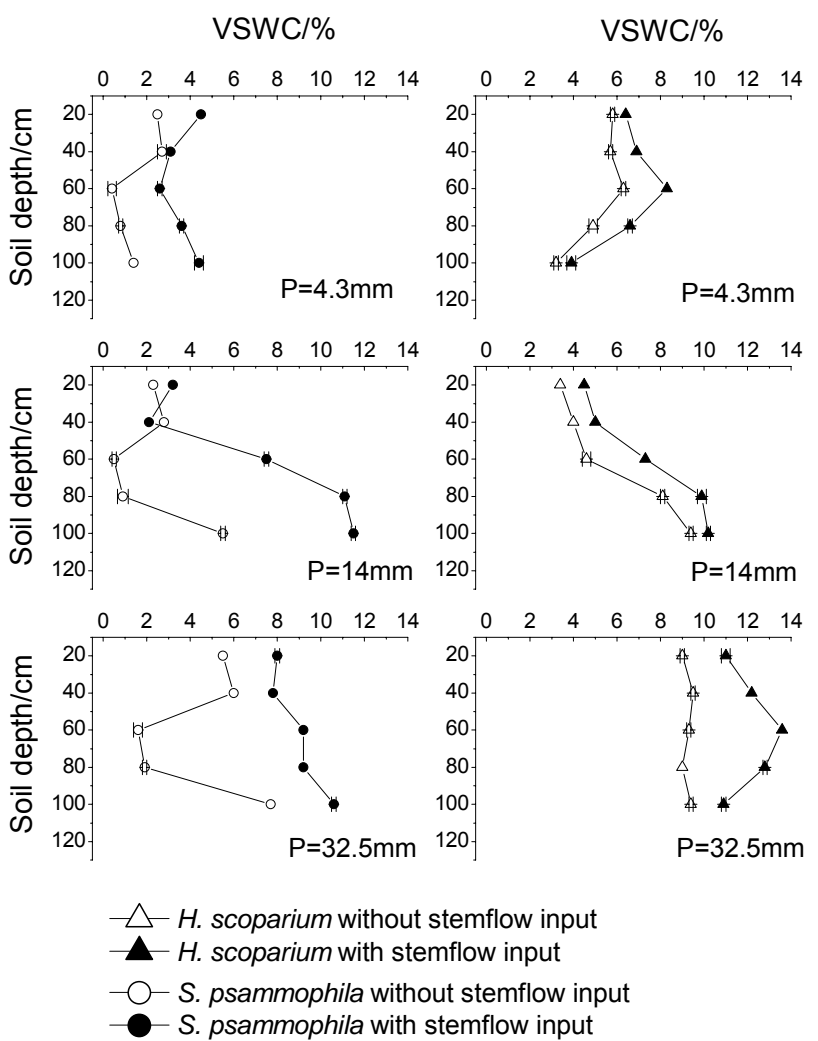

Fig. 9. Distribution of volumetric soil water contents (VSWC) for $H$. scoparium and S. psammophila with and without stemflow under three rainfall events characterized by high, medium and low amounts. Horizontal bars represent the standard error of the three soil moisture measurements.

around the smaller trees with circumferences less than $20 \mathrm{~cm}$. Tanaka et al. (1991) also found that the infiltration area of stemflow increases with increasing diameter of the tree base with a maximum limitation. Owens et al. (2006) had used an impact area of $0.5 \mathrm{~m}^{2}$ around the base of the tree to calculate stemflow funneling ratio for Ashe juniper (Juniperus ashei Buchholz). In our study, stemflow infiltrated within the areal radius of $15-20 \mathrm{~cm}$ around the shrub base (stem diameter averaged $3.6 \mathrm{~cm}$ for $S$. psammophila and $2.2 \mathrm{~cm}$ for H. scoparium) (Fig. 7), therefore funnelling ratios calculated using definition of Herwitz (1986) over-estimated concentration of water near the stem, though Herwitz funnelling ratio has been widely used by many researchers (e.g., Navar, 1993; Levia and Frost, 2003; Levia, 2004; Carlyle-Moses and Price, 2006). The increase of soil water content between with and without stemflow in our study is comparable to the results obtained by Pressland (1976) and Specht (1957). This confirms that stemflow is conducive to concentrate and store water in deeper layers in the soil profile. As in arid and semiarid environments where potential evapotranspiration is many times greater than precipitation, water is the most limiting factor. Previous studies have indicated that redistribu-
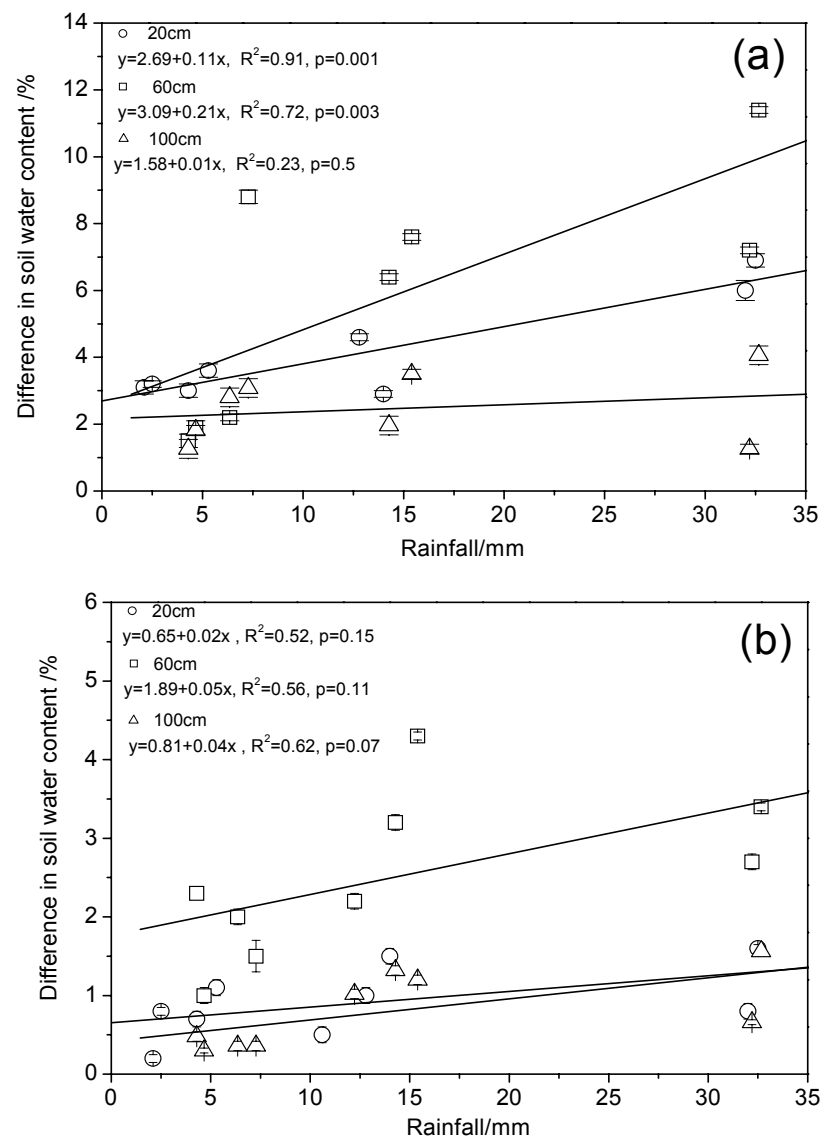

Fig. 10. Difference in volumetric soil water contents between the treatments with and without stemflow at the soil depths of 20,60 and $100 \mathrm{~cm}$ for $S$. psammophila (a) and H. scoparium (b) under different rainfall conditions. Vertical bars represent the standard error of the three soil moisture measurements.

tion of precipitation by funneling water from the canopy towards the base of the plant has been shown to increase the moisture available to individual plants (e.g., Pressland, 1976; Herwitz, 1986; Martinez-Meza and Whitford, 1996; Devitt and Smith, 2002). Hence we speculate that stemflow would be considered as an essential property of desert shrubs that contributes to the stability of shrub communities in harsh environments (Martinez-Meza and Whitford, 1996). For the deciduous forests, Liang et al. (2007) also reported that maximal soil water storage was more than 100 to $200 \%$ of the cumulative open-area rainfall at the points downslope from a tall stewartia stem on a hillslope. They attributed this to concentrated stemflow rapidly flowing into soil layers along the pathways of roots as bypass flow.

Figure 10 shows the differences in soil water contents between the treatments with and without stemflow at the soil depths of 20, 60 and $100 \mathrm{~cm}$ for $H$. scoparium and $S$. psammophila under the 8 rainfall events. The results indicated that the increase of soil water content due to stemflow tended to increase with increasing rainfall amount for both 
shrubs. This is consistent with the above results in Sect. 3.1 that stemflow amount increases with increasing rainfall. Increases of soil water content changes were observed at all depths from 20 to $100 \mathrm{~cm}$. In particular, increase at $60-\mathrm{cm}$ depth was much greater than that in the upper layers (20$\mathrm{cm})$ and deep layers $(100-\mathrm{cm})$. This suggests that stemflow mostly reached $60-\mathrm{cm}$ soil layers and only small portion reached $100-\mathrm{cm}$ soil layers in the study area. Liang et al. (2009) reported that, in the stemflow infiltration process, water flowed rapidly through a deep layer, causing irregular changes in vertical soil water content. This process is very different from the vertical rainfall infiltration process, in which the wetting front expands slowly from the upper layer to the deeper layer. Johnson and Lehmann (2006) found that stemflow has a double contribution to uneven water input and preferential rainwater infiltration that enlarges the heterogeneity of soil water dynamics in forested stands. Therefore, stemflow not only serves as a point source of rainwater on the floor, but also has a high potential to infiltrate multiple soil layers as bypass flow (Liang et al., 2007). The $S$. psammophila had more soil water increase and exhibited significant response to stemflow as compared to the $\mathrm{H}$. scoparium, because $S$. psammophila generated more stemflow during rainfall events.

\section{Conclusions}

This study evidenced stemflow hydrology of two desert shrubs (H. scoparium and S. psammophila) and its impact on the spatial distribution of water flux reaching the soil and its link to preferential flow in the soil profile, which was enhanced by the presence of roots and led to water accumulation in deeper soil layers. The results indicated that, on average, $3.4 \%$ of incident gross rainfall occurred as stemflow for H. scoparium, and $6.3 \%$ for S. psammophila. Stemflow increased linearly with daily precipitation amount, but decreased in a power function with rainfall intensity. The dye tracer experiment proved that root channels were preferential pathways for the movement of most stemflow water into the soil and that preferential flow was more pronounced for rainfall events with higher intensity. Distribution of soil water content under the shrubs with and without stemflow ascertained that stemflow was conducive to concentrate and store water in deeper soil layers, a phenomenon favorable for desert shrub survival in water-limited ecosystems. A clear connection between aboveground stemflow and belowground preferential flow is demonstrated in this study at the individual shrub scale, revealing the importance of integrating ecohydrology and hydropedology in understanding the hydrologic cycle in desert ecosystems.

Acknowledgements. We would like to thank Hans-Jörg Vogel and two anonymous reviewers for their valuable and constructive comments. This study was supported by the National Science Foundation of China (NSFC 40871025 and 40571023) and the National
Key Technologies R\&D Program (Grant No. 2007BAC30B02). We also thank Xiao-Ying Zhang, Wei Wang, Yu-Jun Ma, and Yong-Liang Sun for their helps in conducting the field experiments and observations.

Edited by: H.-J. Vogel

\section{References}

Allison, G. B. and Hughes, M. W.: The use of natural tracers as indicators of soil-water movement in a temperate semi-arid region, J. Hydrol., 60, 157-173, 1983.

Brantley, S. L., White, T. S., White, A. F., Sparks, D., Richter, D., Pregitzer, K., Derry, L., Chorover, J., Chadwick, O., April, R., Anderson, S., and Amundson, R.: Frontiers in Exploration of the Critical Zone, An NSFsponsored Workshop. National Science Foundation, 30 pp., 2006.

Bundt, M., Jaggi, M., Blaser, P., Siegwolf, R., and Hagedorn, F.: Carbon and nitrogen dynamics in preferential flow paths and matrix of a forest soil, Soil Sci. Soc. Am. J., 65, 1529-1538, 2001.

Carlyle-Moses, D. E. and Price, A. G.: Growing-season stemflow production within a deciduous forest of southern Ontario, Hydrol. Process., 20, 3651-3663, 2006.

Carlyle-Moses, D. E.: Throughfall, stemflow and canopy interception loss fluxes in a semi-arid Sierra Madre Oriental matorral community, J. Arid Environ., 58, 181-202, 2004.

Carlyle-Moses, D. E.: Precipitation partitioning by a northern hardwood stand, southern Ontario, Canada: Processes and variability, M.Sc. thesis, University of Toronto, 1996.

Chen, Y. F., Yu, F. H., and Dong, M.: Scale-dependent spatial heterogeneity of vegetation in Mu Us sandy land, a semi-arid area of China, Plant Ecol., 162, 135-142, 2002.

Crockford, R. H. and Richardson D. P.: Partitioning of rainfall into throughfall, stemflow and interception: Effect of forest type, ground cover and climate, Hydrol. Process., 14, 2903-2920, 2000.

De Rooij, G. H.: Modeling fingered flow of water in soils owing to wetting front instability: a review, J. Hydrol., 231-232, 277-294, 2000.

Devitt, D. A. and Smith, S. D.: Root channel macrospores enhance downward movement of water in a Mojave desert ecosystem, J. Arid Environ., 50, 99-108, 2002.

Dong, X. and Zhang, X.: Some observations of the adaptations of sandy shrubs to the arid environment in the Mu Us Sandland: leaf water relations and anatomic features, J. Arid Environ., 48, 41-48, 2001.

Enright, N. J.: Stemflow as a nutrient source for nikau palm (Rhopalostylis sapida) in a New Zealand forest, Aust. J. Ecol., 12, 17-24, 1987.

Flury, M., Fluhler, H., Jury, W. A., and Leuenberger, J.: Susceptibility of soils to preferential flow of water: a field study, Water Resour. Res., 30, 1945-1954, 1994.

Flury, M. and Wai, N. N.: Dyes as tracers for vadose zone hydrology, Rev. Geophys., 41(1), 1002, doi:10.1029/2001RG000109, 2003.

Ford, E. D. and Deans, J. D.: The effects of canopy structure on stemflow, throughfall and interception loss in a young sitka spruce plantation. J. Appl. Ecol., 15, 905-917, 1978. 
Goodall, D.: Plot-less tests of interspecific associations, J. Ecol., 53, 197-210, 1965.

Herwitz, S. R.: Infiltration-excess caused by stemflow in a cycloneprone tropical rainforest, Earth Surf. Proc. Land., 11, 401-412, 1986.

Herwitz, S. R., Levia Jr., D. F.: Mid-winter stemflow drainage from bigtooth aspen (Populus grandidentata Michx.) in central Massachusetts, Hydrol. Process., 11, 169-175, 1997.

Janssen, M. and Lennartz, B.: Characterization of Preferential Flow Pathways through Paddy Bunds with Dye Tracer Tests, Soil Sci. Soc. Am. J., 72, 1756-1766, 2008.

Johnson, M. S. and Lehmann, J.: Double-funneling of trees: Stemflow and root-induced preferential flow, Ecoscience, 13(3), 324333, 2006.

Kung, K. J. S.: Preferential flow in a sandy vadose zone soil, 1. Field observation, Geoderma, 46, 51-58, 1990.

Levia, D. F. and Frost, E. E.: A review and evaluation of stemflow literature in the hydrologic and biogeochemical cycles of forested and agricultural ecosystems, J. Hydrol., 274(1-4), 1-29, 2003.

Levia Jr., D. F.: Differential winter stemflow generation under contrasting storm conditions in a southern New England broadleaved deciduous forest, Hydrol. Process., 18, 1105-1112, 2004.

Li, X. Y., Liu L. Y., Gao, S. Y., Ma, Y. J., and Yang, Z. P.: Stemflow in three shrubs and its effect on soil water enhancement in semiarid loess region of China, Agr. Forest Meteorol., 148, 15011507, 2008.

Liang, W. L., Kosugi, K., and Mizuyama, T.: Heterogeneous soil water dynamics around a tree growing on a steep hillslope, Vadose Zone J., 6(4), 879-889, 2007.

Liang, W.-L., Kosugi, K., and Mizuyama, T.: A three-dimensional model of the effect of stemflow on soil water dynamics around a tree on a hillslope, J. Hydrol., 366, 62-75, 2009.

Lin, H., Bouma, J., Wilding, L., Richardson, J., Kutílek, M., and Nielsen, D. R.: Advances in hydropedology, Adv. Agron., 85, $1-89,2005$

Lin, H.: Hydropedology. Bridging disciplines, scales, and data, Vadose Zone J., 2, 1-11, 2003.

Llorens, P. and Domingo, F.: Rainfall partitioning by vegetation under Mediterranean conditions. A review of studies in Europe, J. Hydrol., 335, 37-54, 2007.

Loik, M. E., Breshears, D. D., Lauenroth, W. K., and Belnap, J.: A multi-scale perspective of water pulses in dryland ecosystems: climatology and ecohydrology of the western USA, Oecologia, 141, 269-281, 2004.

Maitre, D. C. L., Scott, D. F., and Colvin, C.: A review of information on interactions between vegetation and groundwater, Water SA, 25(2), 137-152, 1999.

Martinez-Meza, E. and Whitford, W. G.: Stemflow, throughfall and channelization of stemflow by roots in three Chihuahuan desert shrubs, J. Arid Environ., 32(3), 271-287, 1996.

Mauchamp, A. and Janeau, J. L.: Water funnelling by the crown of Flourensia cernua, a Chihuahuan Desert shrub, J. Arid Environ., 25, 299-306, 1993.

National Research Council: Basic research opportunities in earth science, National Academy Press, Washington, DC, 168 pp., 2001.

Navar, J. and Ryan, R.: Interception loss and rainfall redistribution by three semi-arid growing shrubs in northeastern Mexico, J. Hy- drol., 115, 51-63, 1990.

Navar, J.: The causes of stemflow variation in three semi-arid growing species of northeastern Mexico, J. Hydrol., 145, 165-190, 1993.

Newman, B. D., Wilcox, B. P., Archer, S. R., Breshears, D. D., Dahm, C. N., Duffy, C. J., McDowell, N. G., Phillips, F. M., Scanlon, B. R., and Vivoni, E. R.: Ecohydrology of waterlimited environments: A scientific vision, Water Resour. Res., 42, W06302, doi:10.1029/2005WR004141, 2006.

Nulsen, R. A., Bligh, K. J., Baxter, I. N. E. J. S., and Imrie, D. H.: The fate of rainfall in a mallee and heath vegetated catchment in southern Western Australia, Aust. J. Ecol., 11, 361-371, 1986.

Owens, M. K., Lyons, R. K., and Alejandro, C. L.: Rainfall partitioning within semiarid juniper communities: effects of event size and canopy cover, Hydrol. Process., 20, 3179-3189, 2006.

Parker, G. G.: Throughfall, stemflow in forest nutrition, Adv. Ecol. Res., 13, 57-133, 1983.

Pressland, A. J.: Rainfall partitioning by an arid woodland (Acacia aneura F. Muell.) in south-western Queensland, Aust. J. Bot., 21, 235-245, 1973.

Pressland, A. J.: Soil moisture redistribution as affected by throughfall and stemflow in an arid zone shrub community, Aust. J. Bot., 24, 641-649, 1976.

Runnstrom, M. C.: Rangeland development of the Mu Us Sandy Land in semiarid China: an analysis using Landsat and NOAA remote sensing data, Land Degrad. Develop., 14, 189-202, 2003.

Schwinning, S. and Sala, O. E.: Hierarchy of responses to resource pulses in arid and semi-arid ecosystems, Oecologia, 141, 211220, 2004.

Segal, E., Kushnir, T., Mualem, Y., and Shani, U.: Microsensing of water dynamics and root distributions in sandy soils, Vadose Zone J., 7, 1018-1026, 2008.

Skaggs, T. H. and Shouse, P. J.: Roots and root function: introduction, Vadose Zone J., 7, 1008-1009, 2008.

Slatyer, R. O.: Measurement of precipitation, interception by an arid plant community (Acacia aneura F. Muell.), Arid Zone Res., 25, 181-192, 1965.

Specht, R. L.: Dark Island Heath (Ninety-Mile Plain, South Australia). IV. Soil moisture patterns produced by rainfall interception and stemflow, Aust. J. Bot. 5, 137-150, 1957.

Staelens, J., Schrijver, A. D., Verheyen, K., and Verhoest, N. E. C.: Rainfall partitioning into throughfall, stemflow, and interception within a single beech (Fagus sylvatica L.) canopy: influence of foliation, rain event characteristics, andmeteorology, Hydrol. Process., 22, 33-45, 2008.

Tanaka, T., Tsujimura, M., and Taniguchi, M.: Infiltration area of stemflow-induced water, Ann. Rep., Inst. Geosci., Univ. Tsukuba, 17, 30-32, 1991.

Tromble, J. M.: Water interception by two arid land shrubs, J. Arid Environ., 15, 65-70, 1987.

Wang, Z., Jury, W. A., Tuli, A., and Kim, D.-J.: Unstable Flow during Redistribution in Homogeneous Soil, Vadose Zone J., 2, 52-60, 2003.

Wang, Z., Peng, R. Y., Wang, L., and Liu, L. Y.: Studies on Soil Properties of Aeolian Sandy Land Improvement and Utilization in South Edge of Musu Desert, J. Soil Water Conserv., 20(2), 14-21, 2006 (in Chinese with English abstract).

Wilson, J. T., Leach, L. E., Henson, M., and Jones, J. N.: In situ biorestoration as a ground water remediation technique, Ground 
Water Monit. Rev., 6, 56-64, 1986.

Whitford, W. G., Anderson, J., and Rice, P. M.: Stemflow contribution to the 'fertile island' effect in creosotebush, Larrea tridentata, J. Arid Environ.., 35, 451-457, 1997.
Young, M. H., Lin, H., and Wilcox, B. P.: Introduction to special section on Bridging Hydrology, Soil Science, and Ecology: Hydropedology and Ecohydrology, Geophys. Res. Lett., 34, L24S20, doi:10.1029/2007GL031998, 2007. 